ISSN 1991-8631

Original Paper

http://indexmedicus.afro.who.int

\title{
Development and validation of a simple and economical spectrofluorimetric method for estimation of quinine in pharmaceutical dosage forms
}

\author{
Serigne Omar SARR ${ }^{1,2,}$, Djibril FALL ${ }^{2,3}$, Serigne Momar NDIAYE ${ }^{1}$, \\ Adama DIEDHIOU ${ }^{2,3}$, Amadou DIOP ${ }^{2}$, Bara NDIAYE ${ }^{2}$ and Yérim Mbagnick DIOP ${ }^{1,2}$ \\ ${ }^{1}$ Laboratoire National de Contrôle des Médicaments, 39, Avenue Pasteur, BP 6303, Dakar-étoile, Sénégal. \\ ${ }^{2}$ Laboratoire de Chimie Analytique et Bromatologie, Faculté de Médecine, de Pharmacie et d'Odontologie, \\ Université Cheikh Anta DIOP de Dakar, BP 5005 Dakar-Fann, Sénégal. \\ ${ }^{3}$ Laboratoire de Chimie Organique et Thérapeutique, Faculté de Médecine, de Pharmacie et d'Odontologie, \\ Université Cheikh Anta DIOP de Dakar, BP 5005 Dakar-Fann, Sénégal. \\ *Corresponding author: sosarr1@yahoo.fr
}

\begin{abstract}
A new simple, sensitive, precise, economic and "green" spectrofluorimetric method for the determination of quinine both as a bulk drug and in tablet formulations was developed and validated using water as solvent. At a predetermined excitation wavelength $(330 \mathrm{~nm})$ and emission wavelength $(380 \mathrm{~nm})$, it was proved linear in the concentration range of $50-500 \mathrm{ng} / \mathrm{mL}$, exhibited good correlation coefficient $\left(\mathrm{R}^{2}=\right.$ $0.999)$ and excellent mean recovery $(97.5-103 \%)$. The results of the recovery studies showed that the method was not affected by the presence of common excipients. The method was applied for the analysis of the drug in the pure, tablet and injectable forms. The method was validated for precision, accuracy and recovery studies. Limit of Detection and Limit of Quantification for quinine were found to be $16.6 \mathrm{ng} / \mathrm{mL}$ and $19.8 \mathrm{ng} / \mathrm{mL}$ respectively. The method has been successfully applied for the analysis of marketed formulations available in Senegal.

() 2013 International Formulae Group. All rights reserved.
\end{abstract}

Keywords: Spectrofluorometric analysis, validation, quinine, green method.

\section{INTRODUCTION}

Quinine (6-methoxycinchonan-9-ol) is a cinchona alkaloid that belongs to the aryl amino alcohol group of drugs. The discovery of quinine is considered the most serendipitous medical discovery of the 17th century (Keefe et al., 2012) and malaria treatment with quinine marked the first successful use of a chemical compound to treat an infectious disease (David and Jacob, 2005). It has been used in medicine for ages and has been recognised anti-malaria properties. Quinine is also used for treatment of muscle cramps.

In 1820, quinine was extracted from the bark of the cinchona tree of South America, isolated and named by Pierre Joseph Pelletier and Joseph Caventou. The purified quinine has then replaced the bark in the standard treatment of malaria (Dobson et al., 2001). It remained the antimalarial drug of choice until 1940. Since then, many effective antimalarial drugs have been introduced, although quinine is still used to treat the disease in certain 
critical circumstances, such as severe malaria, and in impoverished regions due to its low cost (Achan et al., 2011, Diener et al., 2002, Galloway et al., 1990, WHO, 1995).

Moreover, quinine is very sensitive to ultraviolet light (UV) and will fluoresce in direct sunlight, due to its highly conjugated resonance structure as shown with the chemical structure in Figure 1.

This native fluorescence is often exploited to analyse quinine. Several researchers have focused on the development of various analytical methods to determine quinine and chloroquine in biological fluids. These chromatographic methods include the use of normal-phase columns (Dua et al., 1993) or reversed-phase columns (Galloway et al., 1990; Beru et al., 1990; Ducharme et al., 1997) after liquid-liquid extraction of the drugs (Croes et al., 1994; Dua et al., 1993) using UV detection (Galloway et al., 1990; Chmurzynski et al., 1997; Mberu et al., 1991; Babalola et al., 1993) or fluorescence detection (Chaulet et al., 1993; Croes et al., 1994; Wanwimolruk, 1996). The latter is better for its greater sensitivity.

Also, compendial methods to analyse quinine in pharmaceutical formulations already existed in Pharmacopoeias. The International Pharmacopeia published by World Health Organization described a titrimetric method (WHO, 1988). However, it is well known that titrimetric methods lack of specificity when compared to spectrofluorimetry for quantitative analysis. The United States Pharmacopea (USP) also published a liquid chromatographic (LC) method with UV detection (USP, 2011). Because of difficulties encountered to run this LC method successfully, our laboratory developed an optimised reversed phase LC method with UV detection to analyse drug formulations containing quinine (Diop et al., 2009).

To date and to our best knowledge, the methods described for the analysis of quinine in pharmaceutical formulations use organic solvents whose difficult removal threatens the environment and sustainable development especially in underdeveloped countries. In the present paper a simple, rapid, sensitive, accurate, specific, economical and reproducible method was developed and validated. Since the drug was found to be freely soluble in water, this solvent was used to develop this spectrofluorimetric method for the determination of quinine as bulk drug and in solid forms.

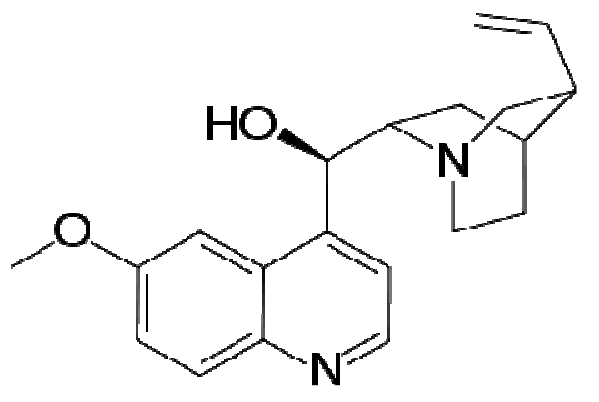

Figure 1: Chemical structure of Quinine.

\section{MATERIALS AND METHODS \\ Reagents}

The quinine standard USP (Rockville, USA) and the Pharmaceutical grade excipients were provided by the Senegalese National Medicines Control Laboratory (LNCM, 39, Avenue Pasteur, Dakar).

Five commercially available formulations codified A, B, C, D and E were purchased from local drugstores and analysed with this method. Distilled water produced in our laboratory with a distiller (GFL, Germany) was used to prepare the solutions. No organic solvent was used. Solutions were filtered through Whatman cellulose filter grade $42^{\circledR}$ (GE Healthcare, France).

\section{Apparatus}

A Perkin Elmer luminescence spectrometer model LS $45^{\circledR}$ (Perkin Elmer instruments, Massachusetts, USA) connected to a Fujitsu Siemens computer loaded with the FLwinlab $^{\circledR}$ application software was used. All the measurements took place in a standard 10 $\mathrm{mm}$ path-length quartz cell, thermo stated at $25.0 \pm 0.5{ }^{\circ} \mathrm{C}$, with $10 \mathrm{~mm}$ bandwidth for the emission and excitation monochromators. 
A Jasco UV/Vis spectrophotometer model V-570 (Jasco instruments, Tokyo, Japan) connected to an IBM computer loaded with the spectra manager application software was used. Working standards were scanned between $200-500 \mathrm{~nm}$ to choose the maximum wavelength absorbance.

\section{Preparation of standard stock and working solutions}

An amount of $5 \mathrm{mg}$ quinine sulfate accurately weighed was transferred in $100 \mathrm{~mL}$ volumetric flask and dissolved with distilled water. A volume of $2 \mathrm{~mL}$ of this solution was again transferred in $200 \mathrm{~mL}$ volumetric flask and completed to the mark with distilled water. An aliquot of this stock standard solution (Qs) was further diluted with distilled water to get working standard solutions $(\mathrm{Qw})$ of 50-100-200-250-300-400-500 ng/mL.

\section{Determination of excitation and emission wavelengths}

Excitation and emission wavelengths were respectively determined at $330 \mathrm{~nm}$ and $380 \mathrm{~nm}$, as described elsewhere (Ramseyer, 2010; Boy and Telchid, 2007). Spectra data were obtained with the Perkin luminescence spectrophotometer.

\section{Statistical analysis}

All experiments were performed in triplicate and the results were expressed as mean values \pm standard deviations (SD). Relative standard deviations (RSD) were also determined. Statistical significance of differences was evaluated using Student's ttest and Fischer-Snedecor F-test at a confidence level of $95 \% \quad(p<0.05)$. Excel software version 2007 (Windows XP) was used to analyse the data.

Cochran's test and Grubbs' test were used to check for high standard deviations and for outlying means.

\section{Method validation}

The method was validated for the following parameters (linearity, precision, accuracy, selectivity, limit of quantification
(LOQ) and limit of detection (LOD)) according to the International Conference Harmonization (ICH) guidelines (ICH, 2005; Swartz and Krull, 2012; Amarouche, 2012).

\section{Linearity and range}

For linearity, five solutions at different concentration (50-100-200-250-300-400-500 $\mathrm{ng} / \mathrm{mL}$ ) were prepared using seven different aliquots of Qs. The data were used for the linearity calibration plot. The limit of detection (LOD) and the limit of quantification (LOQ) were also calculated (ICH, 2005; CEAEQ, 2009; Sai et al., 2012; Swartz and Krull, 2012).

\section{Precision}

Intra-day precision (repeatability) and inter-day precision study (intermediate precision) of the method were assessed at three concentration levels $(250,300$ and 400 $\mathrm{ng} / \mathrm{mL})(\mathrm{n}=3)$ against a qualified reference standard.

The inter-day precision study was performed on three different days i.e day 1, day 2 and day 3 at three different concentration levels $(250,300$ and 400 $\mathrm{ng} / \mathrm{mL}) \quad(\mathrm{n}=3)$. The relative standard deviations (RSD) values were calculated.

\section{Stability studies}

Samples prepared for stability studies were preserved for $48 \mathrm{~h}$ at room temperature and were analysed the following day to test the short-term stability (Maleque et al., 2012).

Accuracy and recovery studies

Accuracy was determined by the recovery studies in the formulation of quinine. Recovery studies were carried out by addition of known quantities of standard drug solution to pre-analysed sample at five different concentrations.

The percentage recoveries were calculated. Accuracy was expressed as relative errors which can be calculated by the equation:

$$
\text { Relative error }(\%)=\frac{\text { Mean determined value }- \text { Theoretical (added amount) }}{\text { Theoretical }}
$$

\section{Specificity in the presence of excipients}

The test for the specificity was carried out using only excipients. Spectra for placebo 
granules, blank, and sample were compared in order to verify interference (Maleque et al., 2012).

\section{Assay of content of Quinine in selected marketed brands}

Five market brands of quinine tablets or bolus were selected at random and analysed using the newly developed and validated method. The powder or suspension of Quinine was accurately weighed or measured and transferred to $200 \mathrm{~mL}$ volumetric flask and made up to the mark with distilled water. The solution was shaken for $20 \mathrm{~min}$. The resulting solution was further diluted with distilled water and filtered through whatman cellulose filter grade 42 . A volume of $1 \mathrm{~mL}$ of the above solution was pipetted out into $200 \mathrm{~mL}$ and $100 \mathrm{~mL}$ volumetric flask and made up to the mark with distilled water. The fluorescence was measured against the blank. The amount of the drug in a sample was calculated from the calibration curve using the following equation:

$$
C Q(\%)=C \exp \times 200(m L) \times 200 \times \frac{W}{W s \times W s t} \times \frac{P}{100} \times C F
$$

Where $C Q$ is the content of quinine per tablet $(\%)$, Cexp is the found concentration based on the fluorescence intensity $(\mathrm{ng} / \mathrm{mL})$, $W s$ is the weight of generic sample powder (g), Wst is the weight of quinine base reference standard powder $(\mathrm{g}), W$ is the average weight of tablet $(\mathrm{g}), P$ is the potency of quinine standard and $C F$ is the conversion factor of Quinine sulfate to Quinine base (0.817).

\section{RESULTS}

Method development and optimisation

Quinine is freely soluble in aqueous medium at concentration much higher than our working and stock solutions. During the development phase, the maximum absorption wavelength appeared at $330 \mathrm{~nm}$ (Figure 2) while the maximum excitation and emission wavelengths appeared respectively at $330 \mathrm{~nm}$ and $380 \mathrm{~nm}$ (Figure 3).
In all cases the analysis time did not exceed five minutes.

\section{Method validation \\ Linearity and range}

The calibration curve was linear over the concentration range $1-500 \mu \mathrm{g} / \mathrm{mL}$ and the regression equation was found to be $\mathrm{y}=0.957$ $\mathrm{x}+14.558$ with correlation coefficient $\left(\mathrm{R}^{2}\right)$ of 0.999. The LOD and LOQ were calculated as $16.6 \mathrm{ng} / \mathrm{mL}$ and $19.8 \mathrm{ng} / \mathrm{mL}$ respectively.

Intra-day and inter-day precision studies

The RSD in precision studies was found to be $0.05-0.3 \%$ (Intra-day) and 0.50 $1.58 \%$ (Inter-day) (Table 1).

\section{Stability studies}

Table 2 shows the short-term stability study results which are in the acceptance range over $48 \mathrm{~h}$.

\section{Accuracy/recovery studies}

The RSD in accuracy studies was calculated at each concentration levels and was found to be less than $0.5 \%$ (Table 3). Also relative error (inaccuracy) values ranged from $-2.5 \%$ to $3 \%$ as shown in Table 3.

\section{Specificity in the presence of excipients}

Figure 3 shows spectra of fluorescence (with their different parts) of pure quinine (a), quinine in the presence of excipients (b) and excipients mixture (c).

\section{Assay of content of Quinine in selected marketed brands}

The proposed method was applied to the determination of quinine tablets (sample A to D) and injectable quinine (sample E) selected at random. The results of these assays yielded $98.58 \%$ to $101 \%$ for tablets and $93.51 \%$ for the sample of injectable quinine (Table 4). All RSDs were less than $1 \%$.

The main characteristics of the developed method are summarized in Table 5. 
Table 1: Intra-day and inter-day precision determined for three different concentrations of quinine $(n=3)$.

\begin{tabular}{ccccccc}
\hline \multicolumn{2}{c}{ intra-day and inter-day precision determined for three different concentrations of quinine } \\
\multicolumn{7}{c}{$(\mathbf{n = 3})$}
\end{tabular}

Table 2: Short-term stability determined by the proposed method $(n=3)$.

\begin{tabular}{|c|c|c|c|}
\hline \multicolumn{4}{|c|}{ short-term stability determined by the proposed method $(n=3)$} \\
\hline \multicolumn{4}{|c|}{ Concentration found } \\
\hline Declared concentration $(\mathrm{ng} / \mathrm{mL})$ & $($ Mean \pm SD ng/mL) & RSD (\%) & Averagepotency (\%) \\
\hline 50 & $51.41 \pm 0.97$ & 1.89 & 102.82 \\
\hline 100 & $94.95 \pm 1.05$ & 1.11 & 94.95 \\
\hline 200 & $192.87 \pm 0.31$ & 0.16 & 96.43 \\
\hline
\end{tabular}

Table 3: Recovery/accuracy for five different concentrations of quinine by the proposed method.

\begin{tabular}{ccccccc}
\hline Dosage & $\begin{array}{c}\text { Label } \\
\text { claim }\end{array}$ & $\begin{array}{c}\text { Amount added } \\
(\%)\end{array}$ & $\begin{array}{c}\text { Amount } \\
\text { found } \pm \text { SD (mg) }\end{array}$ & RSD (\%) & Relative error & \% recovered \\
\hline & & 60 & $156.00 \pm 0.17$ & 0.11 & -2.5 & 97.5 \\
Pre- & & 80 & $185.40 \pm 0.24$ & 0.13 & 3.0 & 103.0 \\
formulated & $100 \mathrm{mg}$ & 100 & $196.60 \pm 0.20$ & 0.10 & -1.7 & 98.3 \\
granules & 120 & $224.40 \pm 0.34$ & 0.15 & 2.0 & 102.0 \\
& & 140 & $238.56 \pm 0.18$ & 0.08 & -0.6 & 99.4 \\
\hline
\end{tabular}


Table 4: Content of quinine in five marketed products determined by the proposed method $(n=3)$.

\begin{tabular}{ccccccc}
\hline \multirow{2}{*}{$\begin{array}{c}\text { Sample } \\
\mathbf{N}^{\circ}\end{array}$} & $\begin{array}{c}\text { Brand name } \\
\text { (code) }\end{array}$ & $\begin{array}{c}\text { Label } \\
\text { claim } \\
(\mathbf{m g})\end{array}$ & \multicolumn{2}{c}{$\begin{array}{c}\text { Concentration } \\
\text { found }(\mathbf{m g})\end{array}$} & \multicolumn{2}{c}{ Drug found (\%) } \\
\cline { 4 - 7 } & & & Mean & SD & RSD (\%) & Mean \\
\hline 1 & A & 250 & 246.45 & 0.08 & 0.03 & 98.58 \\
2 & B & 120 & 119.51 & 0.04 & 0.03 & 99.59 \\
3 & C & 250 & 252.47 & 0.04 & 0.01 & 101.00 \\
4 & D & 120 & 120.02 & 0.06 & 0.05 & 100.02 \\
5 & E & 59.30 & 55.45 & 0.36 & 0.65 & 93.51 \\
\hline
\end{tabular}

Table 5: Main characteristics of the proposed method.

\begin{tabular}{lc}
\hline$\lambda \mathbf{e x}(\mathbf{n m}) / \mathbf{\lambda e m}(\mathbf{n m})$ & $\mathbf{3 3 0 / 3 8 0}$ \\
\hline Intra-day precision (\% RSD) & $0.05-0.33$ \\
Inter-day precision (\% RSD) & $0.50-1.14$ \\
Linearity range (ng/mL) & $50-500$ \\
Accuracy (\% recovery) & $97.5-103$ \\
Regression equation & $\mathrm{Y}=0.957 \mathrm{X}+14.558$ \\
Slope & 0.957 \\
Intercept & 14.558 \\
Correlation coefficient & 0.999 \\
LOD $(\mathrm{ng} / \mathrm{mL})$ & 16.6 \\
LOQ $(\mathrm{ng} / \mathrm{mL})$ & 19.8 \\
\hline
\end{tabular}

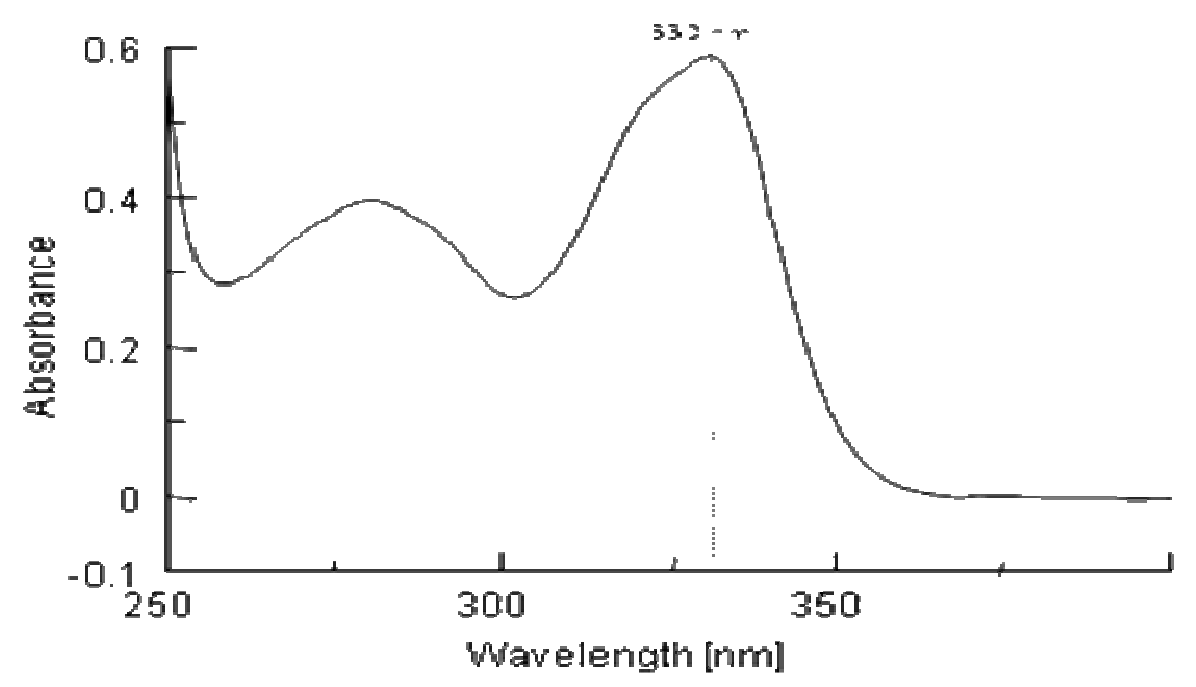

Figure 2: UV spectrum of quinine. 


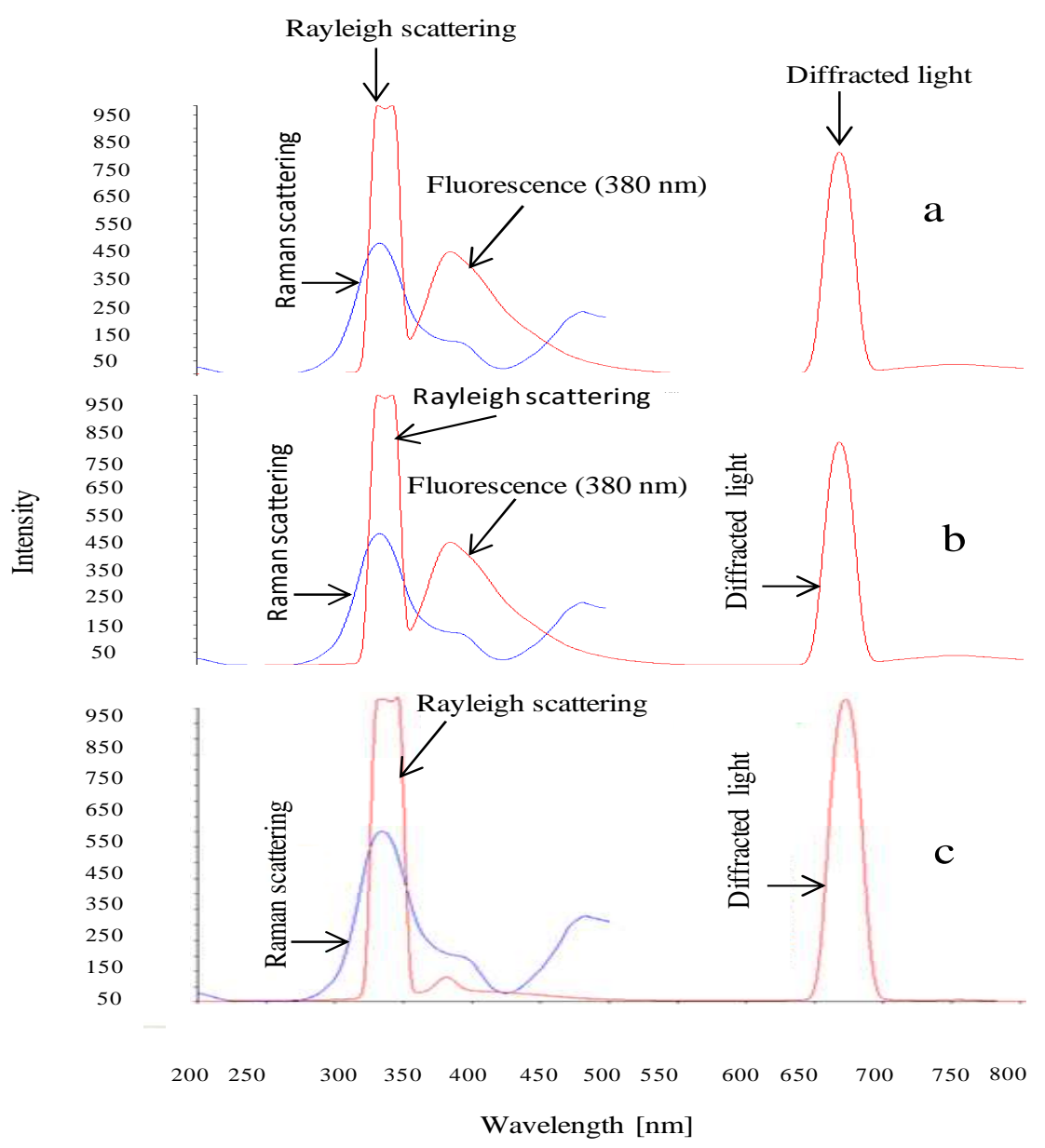

Figure 3: Spectra of fluorescence of pure quinine (a), quinine with excipients (b) and excipients (c).

\section{DISCUSSION}

The correlation coefficient of 0,999 means that the method is linear (Samanidou et al., 2005; Maleque et al., 2012; Amarouche., 2012, Swartz and Krull, 2012). The two concentration limits are measured under repeatability conditions $(\mathrm{n}=6)$. The ration of the two variances $\left(\mathrm{F}_{\text {calc }}\right)$ is compared with $\mathrm{F}_{0,99}$ (Snedecor law) (Gonzalez et al., 2007). Since $F_{\text {calc }}(5,32)<F_{0,99}(10,67)$, the linearity range is acceptable (Gonzalez et al., 2007). A good linear relationship was observed in the concentration range of $1-500 \mathrm{ng} / \mathrm{mL}$. The slope of 0.957 and the low limits of detection and quantification reaching both nanogram per liter indicate clearly that the developed method is very sensitive. These results are in accordance with the sensitivity of fluorimetric analytical techniques (Royer, 1995). It can be concluded that the developed method is sensitive.

Since $\mathrm{C}_{\text {calc }}(0.38)<\mathrm{C}_{0,99}(0.88)$, the Cochran's test revealed no high standard deviations. Also, since $\mathrm{G}_{\text {calc }}<\mathrm{G}_{0,99}$ (1.97) (for all means at each concentration level), the Grubbs' test showed no outlying means.

Results within the range of $97.5 \%$ $103 \%$ ensure an accurate method (Maleque et al., 2012). Also relative error (inaccuracy) values ranging from $-2.5 \%$ to $3.0 \%$ as shown 
in table 3 can be considered as excellent and indicate a lack of interference with the excipients of formulations. No significant difference was observed between the mean values of amounts added and found ( $p>0.05$ ). Also Student's t-test for significance of slope $(0,957)$ and interceipt (14.558) revealed no interference. It can be concluded that the method is specific (Maleque et al., 2012). The results obtained were reproducible with excellent percentage recoveries and low RSD values.

Figure 2 shows the UV absorption spectrum of pure quinine while Figure 3 shows spectra of fluorescence of pure quinine (Figure 3a), quinine in presence of excipients (Figure 3b) and excipients mixture (Figure 3c). No fluorescence was noted with excipients (Figure 3c) at the maximum emission wavelength $(380 \mathrm{~nm})$. The fluorescence curve at $380 \mathrm{~nm}$ (specific to Quinine) appears only in Figures $3 \mathrm{a}$ and $3 \mathrm{~b}$ as expected. For the Figures $3 a, 3 b$ and $3 c$, the curve at the excitation wavelength $(330 \mathrm{~nm})$ is known as Raman scattering and due to inelastic scattering in solvents. This curve is always close to the curve known as Rayleigh scattering (elastic scattering) always more intense (Rouessac et al., 2009). The result shown in Figure $3 \mathrm{c}$ is in accordance with excipients chemical structures. Then the developed method is accurate and specific for the analysis of drugs without prior extraction.

The high sensitivity and selectivity of this technique made possible the development of many applications, particularly in the field of analysis of medicinal natural substances and their metabolites in biological fluids (Samanidou et al., 2005).

Low values of RSD ranging from $0.08 \%$ to $0.15 \%$ also indicate the suitability of this method for the analysis of quinine formulation and commercially available dosage forms (tablets and injection).

The RSD in precision studies was found to be $0.05-0.33 \%$ (Intra-day) and 0.50$1.58 \%$ (Inter-day) (Table 1). The intra-day and inter-day precision studies (Table 1) of the developed method confirmed adequate sample stability and method reliability where all the RSDs were $<2 \%$. These results clearly indicate that the method is precise enough for the analysis of the drug.

Table 2 shows the short-term stability study results which are in the acceptance range over $24 \mathrm{~h}$. Stability studies were in the acceptance range (Table 2) with average potencies ranged from $94.95 \%$ to $102.82 \%$ with RSD $<2 \%$ at each level, after one day storage at room temperature (Maleque et al., 2012).

The Quinine content of five marketed products (four tablets samples coded A to D and one injectable sample coded E) evaluated with this new method was in good agreement with the label claims and the Pharmacopeia's specifications (WHO, 1988; USP, 2011). The results of these assays yielded $98.58 \%-101 \%$ for tablets and $93.51 \%$ for the injectable quinine sample. All calculated RSDs values were less than $1 \%$. These values meet official requirements $(\mathrm{ICH}, 2005)$ and many authors considered that these values are very satisfactory (Samanidou et al., 2005; Maleque et al., 2012; Swartz and Krull, 2012).

To our best knowledge, this analytical fluorimetric method is the first method using water as exclusive solvent without any trace of organic solvent. Such a method can be called "green analytical technique".

The developed fluorimetric method is simple, accurate, precise and selective for the estimation of quinine in solid and suspension forms. The high percentage recoveries obtained in Table 4 for various amounts of quinine in formulated mixture with excipients (such as starch, gelatin, gum arabic and talc) suggested that there is no interference. Evidence is made by the lack of absorbance at the specified wavelength for the excipients and blank solutions.

Several studies have described various problems related to the quality of quinine drug (Lon et al., 2006; Kayumba et al., 2004; 
Evans et al., 2012; Pribluda et al., 2012). In this context, national drug regulators need to strengthen their roles in the monitoring of anti-malarial drug quality using simple, economical and precise analytical methods like this newly developed method.

\section{Conclusion}

The proposed method is simple and precise and do not suffer from any interference due to common excipients of marketed drugs. The method is linear in the concentration range of $50-500 \mathrm{ng} / \mathrm{mL}$. Futhermore, the limit of detection, the simplicity of the procedure and the short analysis time (approximately $5 \mathrm{~min}$ ) in comparison with the already published methods should allow this method to be a useful tool for the routine analysis of quinine. In developing countries, substandard drugs are a major concern in the management of malaria.This method can easily be used for monitoring the quality of quinine-based medicines.

\section{REFERENCES}

Achan J, Talisuna AO, Erhart A, Yeka A, Tibenderana JK, Baliraine FN, Rosenthal PJ, D'Alessandro U. 2011. Quinine, an old anti-malarial drug in a modern world: role in the treatment of malaria. Malar. J., 10:144.

Amarouche S. 2012. Caractérisation d'une méthode de mesure : étape clé dans le processus de validation. Tech. Ing., 1040: $1-14$.

Babalola CP, Bolaji OO, Dixon PAF, Ogunbona FA. 1993. Column liquid chromatographic analysis of quinine in human plasma, saliva and urine. $J$. Chromatogr. Biomed. Appl., 127: 151154.

Boy J, Telchid I. 2007. Dosage de la Quinine dans des boissons gazeuses par spectroscopie fluorescence et HPLC-UV. http://www.m2proanalytique.ups-tlse.fr/ 2007quinine.pdf, accessed on July $20^{\text {th }}$ 2012.

CEAEQ. 2009. Centre d'expertise en analyse environnementale du Québec. Protocole pour la validation d'une méthode d'analyse en chimie. [electronic document]. Programme d'accréditation des laboratoires d'analyse, available on http://www.ceaeq.gouv.qc.ca /accredita tion/pala/DR12VMC_protocole_val_chi mie.pdf, accessed on August $5^{\text {th }} 2012$.

Chaulet JF, Robert Y, Prevosto JM, Soares O. 1993. Simultaneous determination of chloroquine and quinine in human biological fluids by high-performance liquid chromatography. J. Chromatogr., 613(2): 303-310.

Chmurzynski LJ. 1997. High-performance liquid chromatographic determination of quinine in rat biological fluids. $J$. Chromatogr. B. Biomed. Appl., 693(2): 423-429.

Croes K, McCarthy PT, Flanagan RJ. 1994. Simple and rapid HPLC of quinine, hydroxychloroquine, chloroquine, and desethylchloroquine in serum, whole blood, and filter paper-adsorbed dry blood. Anal. Toxicol., 18(5): 255-260.

David B, Jacoby RMY. 2005. Encyclopedia of Family Health ( $3^{\text {rd }}$ edn). Marshall Cavendish: New York.

Diener HC, Dethlefsen U, Dethlefsen-Gruber S, Verbeek P. 2002. Effectiveness of quinine in treating muscle cramps. $J$. Clin. Pract., 56: 243-246.

Diop YM, Sakho M, Diop A, Ndiaye B, Diedhiou A, Sarr SO. 2009. Développement et validation d'une méthode de dosage de la quinine et de ses homologues. Ann. Fals. Exp. Chim., 971: $18-22$.

Dobson S. 2001. The history of antimalarial drugs. In Antimalarial Chemotherapy: Mechanisms of Action, Resistance, and New Directions in Drug Discovery, Totowa PJR (ed). Humana Press: New Jersey; 15-25. 
Dua VK, Sarin R, Prakash A. 1993. Determination of quinine in serum, plasma, red blood cells and whole blood in healthy and Plasmodium falciparum malaria cases by high-performance liquid chromatography. J. Chromatogr., 614: 87-93.

Ducharme J, Farinotti R. 1997. Rapid and simple method to determine chloroquine and its desethylated metabolites in human microsomes by high-performance liquid chromatography with fluorescence detection. J. Chromatogr. B., 698: 243250.

Evans L, Coignez V, Barojas A, Bempong D, Bradby S, Dijiba Y, James M, Bretas G, Adhin M, Ceron N, Hinds-Semple A, Chibwe K, Lukulay P, Pribluda V. 2012. Quality of anti-malarials collected in the private and informal sectors in Guyana and Suriname. Malar. J., 11: 203.

Galloway JH, Marsh D, Forrest ARW. 1990. A simple and rapid method for the estimation of quinine using reversedphase high-performance liquid chromatography with UV detection. J. Anal. Toxicol., 14(6): 345-347.

Gonzalez C, Prichard E, Spinelli S, Gille J, Touraud E. 2007. Validation procedure for existing and emerging screening methods. Trends Anal. Chem., 26(4): 315-322.

ICH. 2005. Validation of Analytical Procedures: Text and Methodology, International Conference on Harmonization (ICH), Q2(R1), Geneva, Switzerland.

Kayumba PC, Risha PG, Shewiyo D, Msami A, Masuki G, Ameye D, Vergote G, Ntawukuliryayo JD, Remon JP, Vervaet C. 2004. The quality of essential antimicrobial and antimalarial drugs marketed in Rwanda and Tanzania: influence of tropical storage conditions on in vitro dissolution. J. Clin. Pharm. Ther., 29(4): 331-338.
Keefe S. 2012. How was quinine discovered? Available on http://www.ehow.com/ facts_5828007_quinine accessed on July $11^{\text {th }}, 2012$.

Lon CT, Tsuyuoka R, Phanouvong S, Nivanna N, Socheat D, Sokhan C, Blum N, Christophel EM, Smine A. 2006. Counterfeit and substandard antimalarial drugs in Cambodia. Trans. R. Soc. Trop. Med. Hyg., 100(11): 1019-1024.

Mberu EK, Ward SA, Winstanley PA, Watkins WM. 1991. Measurement of quinine in filter paper absorbed blood by high performance chromatography. $J$. Chromatogr. Biomed. Appl., 108: 180184.

Pribluda VS, Barojas A, Añez A, López CG, Figueroa R, Herrera R, Nakao G, Nogueira FHA, Pianetti GA, Povoa MM, Viana GMR, Gomes MS, Escobar JP, Sierra O L, Norena SP, Veloz R, Bravo M, Aldás MR, HindsSemple A, Collins M, Ceron N, Krishnalall K, Adhin M, Bretas G, Hernandez N, Mendoza M, Smine A, Chibwe K, Lukulay P, Evans L. 2012. Implementation of basic quality control tests for malaria medicines in Amazon Basin countries: results for the 2005-2010 period. Malar. J., 11: 202.

Ramseyer J. 2010. Mesure de la contamination chimique croisée lors de la préparation d'injectables et de formes sèches de médicaments toxiques. [electronic document]. Available on http://pharmacie.hug ge.ch/ens/ travmaitrise/2010_contamination_ramsey er.pdf, accessed on July $14^{\text {th }}, 2012$.

Royer AC. 1995. Approaches to teaching fluorescence spectroscopy. Biophys. J., 68(3): 1191-1195.

Rouessac F, Rouessac A, Cruché D, Duverger-Arfuso C, Martel A. 2009. Analyse chimique. Méthodes et Techniques Instrumentales $\left(7^{\text {th }}\right.$ edn). Dunod: Paris; 227-254.

Sai B, Kumar P, Mathrusri-Annapurna M, Pavani S. 2012. Development and 
validation of a stability indicating RPHPLC method for the determination of Rufinamide. J. Pharm. Analysis., http://dx.doi.org/10.1016/j.jpha.2012.08.0 03.

Samanidou VF, Evaggelopoulou EN, Papadoyannis IN. 2005. Simultaneous determination of quinine and chloroquine antimalarial agents in pharmaceuticals and biological fluids by HPLC. J. Pharm. Biomed. Analysis., 38: 21-28.

Swartz ME, Krull IS. 2012. Handbook of Analytical Validation. CRC Press: New York.

USP (United States Pharmacopeia). 2011. National Formulary.NF29, Rockville, The United States Pharmocopeial Convention, 4106-4107.
Wanwimolruk S, Wong SM, Zhang H, Coville PF. 1996. Simultaneous determination of quinine and a major metabolite 3hydroxyquinine in biological fluids by HPLC without extraction. J. Liq. Chromatogr. Relat. Tech., 19: 293-305.

WHO. 1988. World Health Organization. The International Pharmacopoeia. Quality Specifications, ( $3^{\text {rd }}$ edn). World Health Organization: Geneva.

WHO. 1995. World Health Organization. Model Prescribing Information. Drugs Used in Parasitic Diseases (2 ${ }^{\text {nd }}$ edn). World Health Organization: Geneva. 